\title{
"Önce Zarar Verme" Epidermolizis Bülloza Hastalarında Anestezi Yönetimi ve Hasta Özellikleri; Retrospektif Analiz
}

\section{"Primum Non Nocere" Anesthesia Management and Patient Characteristics of Epidermolysis Bullosa Patients; Retrospective Analysis

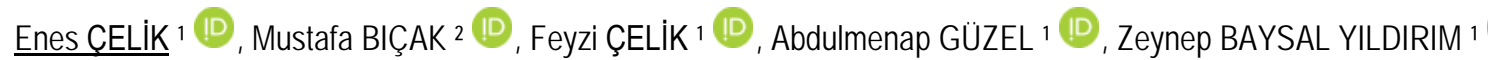

1 Dicle Üniversitesi Tıp Fakültesi, Anesteziyoloji ve Reanimasyon AD, Diyarbakır, Türkiye

2 Diyarbakır SBÜ Gazi Yaşargil Eğitim ve Araştırma Hastanesi, Anestezi Kliniği, Diyarbakır, Türkiye

Öz.

Amaç: Bu retrospektif çalışmanın amacı, hastanemizde ameliyat olan epidermoid bülloza hastalarıın ameliyat endikasyonlarını, özelliklerini ve anestezi yönetimini değerlendirmektir.

Materyal ve Metod: Bu çalışmada bu hasta grubunun hastane bilgi sistemindeki kayıtları ve anestezi kayıtları incelendi. Hastaların demografik verileri, preoperatif özellikleri, cerrahi endikasyonu, anestezi tekniği, kan transfüzyonu ve komplikasyonları kaydedildi.

Bulgular: Toplam 19 hasta çalışmaya dahil edildi. Hastaların bir kısmı birden fazla defa ameliyat olduğundan 25 ameliyat verisi kullanıldı. Hastaların tamamının kontraktür açılması ve psödosindaktili nedeniyle opere olduğu görüldü. Hastaların tamamında genel anestezi uygulandı. Hiçbirinde postoperatif yeni lezyon gözlenmedi.

Sonuç: Kelebek hastalığı olarak da bilinen bu hasta grubunda peroperatif hasta yönetimine dikkat edilmeli anestezinin her aşamasında oluşabilecek komplikasyonlara karşı hazırlıklı olunmalıdır. Epidermoid Bülloza hastalarında minör travmalarla bile hastaların hayatını etkileyen lezyonlar oluşabileceği hatırda tutulmalı. Ve önceliğimiz tıbbın ilk kuralı olan "önce zarar verme" olmalıdır.

Anahtar Kelimeler: Epidermolizis Bülloza, Genel anestezi, Perioperatif bakım, Zor havayolu

\section{Abstract}

Background: The aim of this retrospective study was to evaluate the indications, characteristics and anesthesia management of epidermoid bullosa patients who underwent surgery in our hospital.

Materials and Methods: In this study, records of this patient group in the hospital information system and anesthesia records were examined. Demographic data, preoperative characteristics, surgical indication, anesthesia technique, blood transfusion and complications were recorded.

Results: A total of 19 patients were included in the study. Since some of the patients had multiple operations, 25 surgical data were used. All patients were operated due to contracture release and pseudo syndactyly. All patients underwent general anesthesia. No new postoperative lesions were observed.

Conclusions: In this patient group, also known as butterfly disease, attention should be paid to the management of the patient perioperatively and be prepared for the complications that may occur in each stage of anesthesia. It should be kept in mind that even minor traumas in epidermoid bullosa patients may cause lesions that affect patients' lives. And our priority should be the first rule of medicine, "Primum Non Nocere"

Key words: Epidermolysis bullosa, General anesthesia, Perioperative care, Difficult airway 


\section{Giriş}

Epidermolizis Bülloza (EB), nadir görülen, herediter bir hastalıktır. EB deri ve müköz membranlarda günlük minimal sürtünme, travmayla ödem ve devamında vezikülobüllöz lezyonlar oluşumudur (1). Sıklıkla otozomal resesif kalıtım izlenen EB'nin insidansı 1/50000-1/500000 olarak tanımlanmaktadır (2). Bu hastalar yaşadıkları cilt problemleri nedeniyle yaşamları boyunca pek çok kere cerrahi operasyon geçirmek zorunda kalırlar. Bu operasyonlar; özefagus darlığı nedeniyle özefagus balon dilatasyonu, kontraktürler ve cilt lezyonları nedeniyle psödosindaktili serbestleştirilmesi, cilt grefti ve dental girişimlerdir (3).

Epidermoid Bülloza hastalarında zor havayolu olasılığı, porfirya sıklığında artış, gelişme geriliği, ödem ve anemi, hipoalbuminemi gibi ek özellikler nedeniyle anestezi yönetimi özellik arzeder. Özellikle bu hastalarda minör travmayla bile gelişen cilt lezyonları akılda tutulmalı ve buna göre anestezi yönetiminin yanında peroperatif bakım da önceden planlanmalıdır.

Bu retrospektif çalışmanın amacı EB hastalarının ameliyat sürecini gözden geçirmek, peroperatif anestezi yönetimi, zor havayolu sıklığı ve karşılaşılan problemleri belirlemektir. Bu özelikli hasta grubu için ideal bir anestezi yönetim stratejisini literatür eşliğinde sunmaktır.

\section{Materyal ve Metod}

Dicle Üniversitesi Tıp Fakültesi Uygulama ve Araştırma Hastanesinde Ocak 2012-Nisan 2018 tarihleri arasında psödosindaktili ve kontraktür tedavisi nedeniyle ameliyat olan EB hastalarının dosyaları ve hastane bilgisayar sistemindeki kayıtları Dicle Üniversitesi Tıp Fakültesi Girişimsel Olmayan Klinik Araştırmalar Etik Kurulunun onayı alındıktan sonra (no:157 - Tarih: 18.05.2018) retrospektif olarak incelendi.

Hastaların preoperatif değerlendirmelerinde laboratuar değerleri, hava yolu değerlendirilmesi ayrıntılı incelenerek kayıt edildi. Özellikle monitörizasyon sırasında dikkat edilmesi konusunda anestezi değerlendirme formuna not düşüldü. Bu hastaların ameliyatları planlanırken cerrahi ekip ile görüşülerek operasyon günü ameliyat listesinde ilk hasta olmalarına dikkat edildi.

Hastalara mümkün olabildiğince standart anestezi monitörizasyonu (EKG, noninvaziv arter basıncı, oksijen satürasyonu, vucüt sıcaklığı) uygulandı. Kullanılacak maske ve bleydler su bazlı jel ile kayganlaştırıldı. Hastanın altındaki örtünün düz ve yumuşak olmasına özen gösterildi. Hastaların gözleri korneal abrazyondan koruma amaçlı pomad ile kapatıldı.

Opere olan hastaların tamamına genel anestezi uygulandı. Anestezi indüksiyonunda midazolam $2 \mathrm{mg} / \mathrm{kg}$, propofol 2 $\mathrm{mg} / \mathrm{kg}$, fentanil $2 \mu \mathrm{g} / \mathrm{kg}$, rokuronyum $0,6 \mathrm{mg} / \mathrm{kg}$ ve idamede sevofluran \% 2-3, oksijen-hava (\%50-50) kullanıldı. Postoperatif analjezi amacıyla multimodal ağrı yaklaşımı tercih edildi. Parasetamol $10 \mathrm{mg} / \mathrm{kg}$ ve tramadol $2 \mathrm{mg} / \mathrm{kg}$ uygulandı. Hastaların tamamında sugammadeks $4 \mathrm{mg} / \mathrm{kg}$ uygulanarak ekstübasyon sağlandı.

Peroperatif süreçte hastalarda yeni bül oluşumuna rastlanmadı. Mortal seyreden vaka olmadı. Hastalar postoperatif derlenme ünitesinden kliniğe transfer edildi.

Hastaların bilgileri taranırken anestezi süresi, cerrahi süresi, yatı̧s süresi, ameliyat öncesi laboratuar tetkikleri, yaşkilo-cinsiyet gibi demografik verileri, zor entübasyon sıkığı ve anestezi yönetiminde kullanılan ilaç ve malzemeler kaydedildi.

Toplanan veriler tanımlayıcı ve kategorilere ayıran grafiklerle gösterildi. Ortalama değerler ve bazı verilerin sıkığı çalışıldı.

\section{Bulgular}

Psödosindaktili ve kontraktür açılması amacıyla opere olan toplam 19 EB hastası çalışmaya dahil edildi. Bu hastalardan 6 tanesi aynı endikasyonlarla ikinci defa opere edildi. Hastaların 9 tanesi erkek, 10 tanesi kadın cinsiyetteydi. Kontraktür ve psödosindaktili hastalarının eklem fonksiyonlarını kaybetmeden erken safhada opere olması gerektiğinden yaş ortalamasının 11,88 olduğu görüldü (Grafik 1). Hastaların Mallampati skoru ağız açıklıkları kısıtı olduğu için değerlendirilemedi. Bunun yerine zor havayolu olasillğını değerlendirmek amacıyla Tiromental mesafe ölçümü, Üst dudak ısırma testi ve ağız açıklığı ölçümü yapıldı. Çoğu hastada ağız açıkığının 3 santimetreden daha az olduğu görüldü. Hastalar geneli ASA değeri II olarak saptandı Anestezi polikliniğinde tam kan sayımı ve biyokimya paremetreleri çalışıldı. Ameliyat öncesi ortalama albümin değeri: 3.04 g/dl, ortalama hematokrit düzeyi: $34.34 \%$ olarak saptandı (Grafik 2).

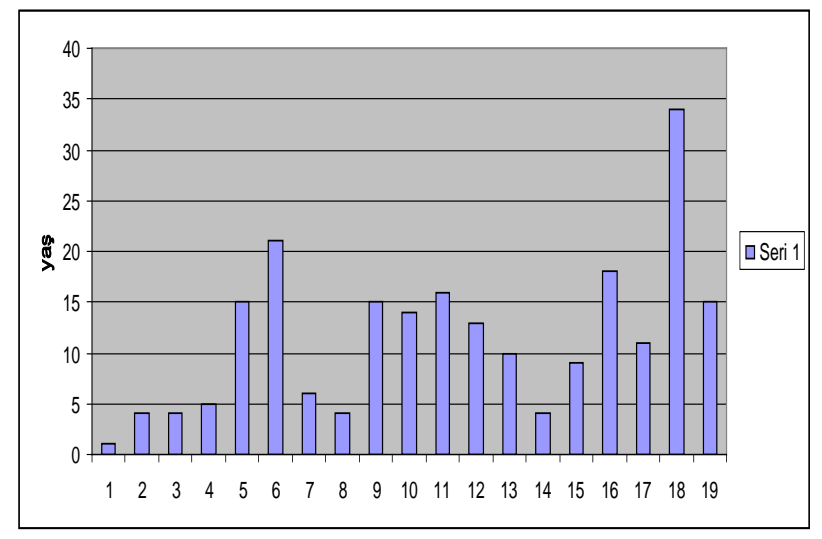

Grafik 1. Hastaların yaş dağııımı

Preoperatif değerlendirmede hastaların hepsinde gelişme geriliği ve yaşa göre vücut ağırlıklarının düşük olduğu görüldü. Hastaların vücut ağırlığı ortalamasının $28,3 \mathrm{~kg}$ olduğu ve kiloya göre persantil değerlerinin düşük olduğu görüldü.

Operasyonlarda ortalama cerrahi süre: $148.8 \mathrm{dk}$, ortalama anestezi süresi:167,1 dk olduğu görüldü. 
Hastaların ortalama hastanede toplam yatış süresinin 12 gün olduğu görüldü.

Hastalarda bildirilmiş en sık komplikasyonlar zor havayolu, operasyon sonrası gelişen yeni cilt lezyonları ve büllerdir. Fakat bizim takip ettiğimiz hastalarda peropretif dönemde tüm ameliyathane ekibi hasta hakkında bilgilendirildiği ve videolaringoskop ile entübasyon yapıldığından bu komplikasyonlar yaşanmadı.

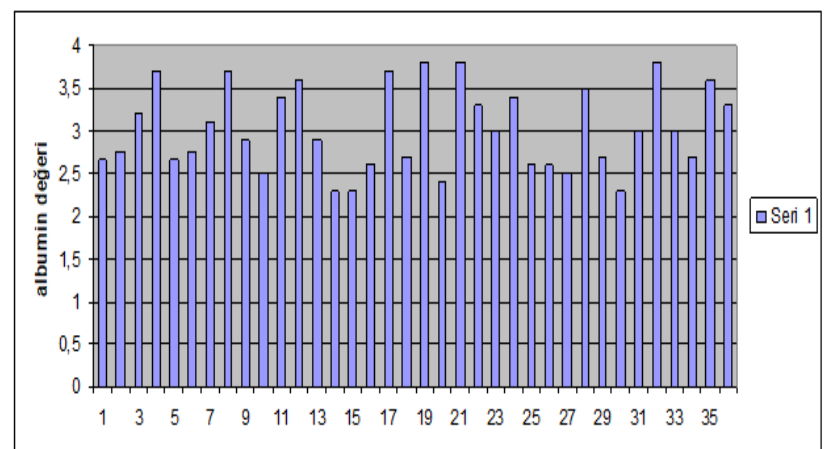

Grafik 2. Hastaların kan Albumin değeri g/dl

\section{Tartışma}

Epidermoid Bülloza hastalarının anestezisi planlanırken öncelikle "primum non nocere" yani; önce zarar verme sözü hatırda tutulmalıdır. Bu hastalar kırılgan yapıları ve komorbiditeleri nedeniyle multidisipliner bir yaklaşımla yönetilmelidir.

Epidermoid Bülloza hastaları yaşamları boyunca tanı veya tedavi işlemleri gibi pek çok sebepten dolayı genel anestezi intiyacı duymaktadırlar.

Epidermolizis bülloza hastalarının preoperatif değerlendirilmesi özelliklidir. Bu hastaların preoperatif dönemde değerlendirilmesinde beslenme bozukluğuna bağlı hipoproteinemi, gelişme geriliği nedeniyle laboratuar değerlendirmesi gereklidir.

Çalışmamızda hastalardan preoperatif değerlendirmede önerilen tam kan sayımı, tam idrar tetkiki, elektrolitler ve kan üre azotu çalışıldı.

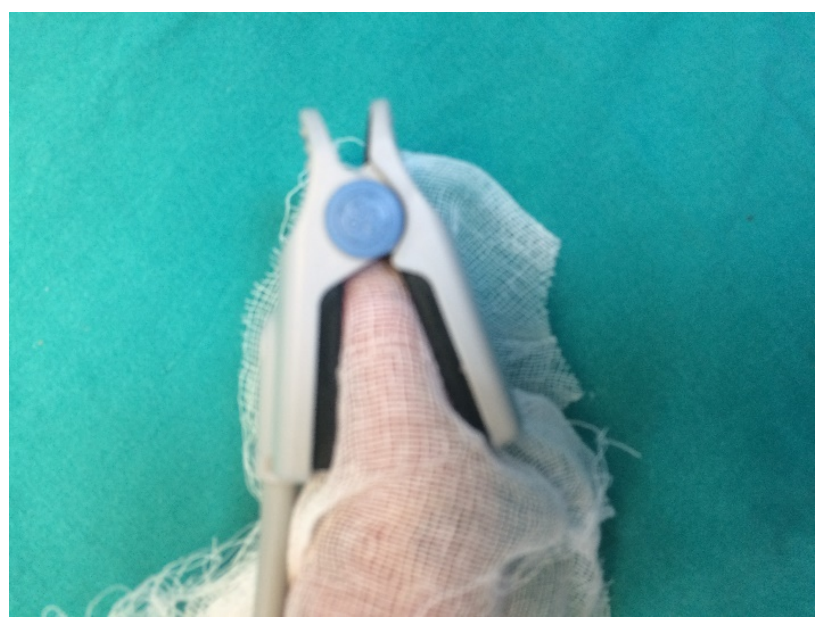

Şekil 1. Clip-on saturasyon probu
Ayrıca temporomandibular eklemde hareket kısıtlılığına bağlı ağız açıklığının az olması ve buna bağlı Mallampati skorunun değerlendirilememesi nedeniyle bu hastaların tümü zor entübasyon/havayolu olarak kabul edilmelidir(4). Hastalara önerilen standart anestezi monitorizasyonu uygulanmalı ve invaziv girişimler sırasında oluşabilecek mekanik travma en aza indirilmelidir. Biz de bu hastalarda EKG monitörizasyonu yaparken elektrot kullanmamaya, kullanılan durumlarda elektrotların altına ekstra jel eklemeye veya boyutunu küçültülmeye özen gösterdik(5). Anestezi ekibi olarak nitril eldiven kullandık ve bu eldivenlere hassasiyet gözlenmedi. Noninvaziv tansiyon aletinin manşonun altını pamuk ile sardık. Saturasyon probu olarak clip-on prob tercih ettik(6)(Şekil 1). Ve kalp atım hızı monitörizasyonu için de saturasyon probu kullanıldı.

Hastaların damar yolunun sabitlenmesi amacıyla da yapışkan bantların neden olduğu cilt ayrışmasından korunmak için sargı bezi kullanıldı(Şekil 2). Bilindiği gibi genel anestezi esnasında gözlerin açık kalması korneal abrazyon gelişimine neden olmaktadır. Bunu engellemek amacıyla antibiyotikli göz pomadları kullanıldı.

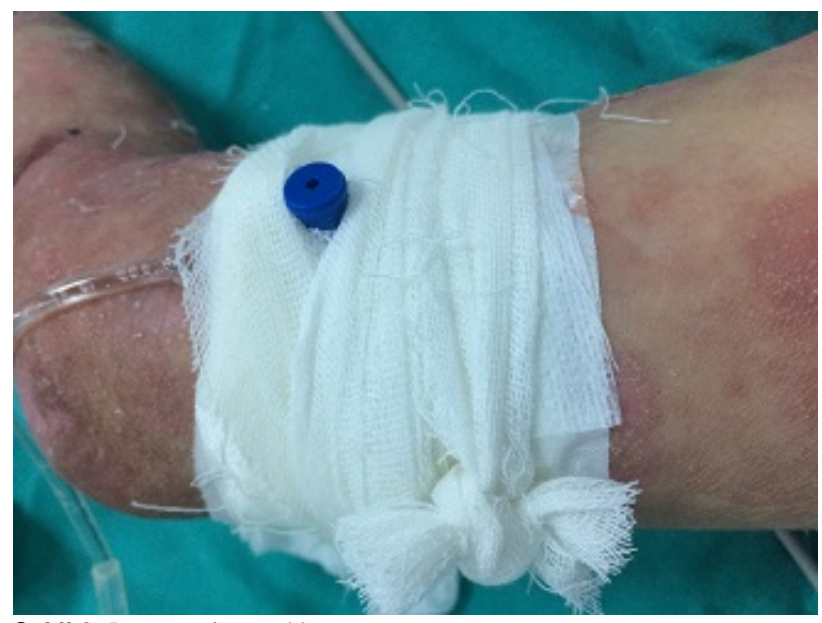

Şekil 2. Damaryolu tespiti

Bu hasta grubunda kronik enfeksiyon, anemi, el ve ayaklarda travmaya en sık maruz kalan bölgeler olması nedeniyle yapışıklık ve kontraktürlere bağlı parmak deformitelerine sık rastlanır. Ayrıca yeni cilt lezyonları kolayca gelişebileceği için ve kontraktürleri nedeniyle pozisyon verirken özel ilgi ve dikkat gerektiği unutulmamalıdır. Hastalarımıza pozisyon verirken özellikle eklem bölgelerine özel silikon yastıklar kullandık.

Anestezi hazırlığı yapılırken zor havayolu olasılığının yüksek olması ve en korkulan komplikasyon olması nedeniyle değişik boylarda bleydler, videolaringoskop, değişik ebatlarda supraglottik havayolu aletleri hazır bulunduruldu. Kliniğimizde fiberoptik entübasyon cihazı bulunmadığından trakeotomi açısından Kulak Burun Boğaz ekibi ile irtibata geçildi. Hastaların ikisinde I-gell, kalan on yedi hastada endotrakeal entübasyon ile havayolu sağlandı. Entübasyon 
aşamasında çoğu hastada Cormack-Lehane skoru 3 olarak değerlendirildi. Hastalarımızda gelişme geriliği olduğundan kaflı ve normale göre bir numara daha küçük tüpler tercih edildi.

Anestezikler kanda özellikle albumine, alfa-1 glikoproteine ve hemoglobine bağlanırlar. Epidermoid Büllosa hastalarında mevcut olan hipoproteinemi nedeniyle ilaç dozları gözden geçirilmelidir. Beslenmeye bağlı protein eksikliğinde proteinlere bağlanma kapasitesi azalabilir. Bu durumlarda serbest ilaç miktarı artacağından, yan etkileri ortaya çıkabilir ve ilaçların etkileri şiddetlenebilir. Bu nedenle ilaç dozları azaltılmalıdır. Biz de çalışmamızda indüksiyon için kullandığımız intravenöz ajanların dozunu azaltarak ve titre ederek uyguladık. Genel anestezinin idamesinde literatürde önerildiği gibi tüm hastalarda inhalasyon anesteziği olarak Sevofluranı tercih ettik (7).

Epidermolizis büllosa hastalarının dental cerrahi gibi operasyonlarında ketamin ile sedasyon ve kontraktür operasyonlarında periferik sinir blokları tercih edilen diğer anestezi teknikleridir(8). Ekstübasyon aşamasında ağız içindeki sekresyonlar aspire edilirken dikkatli davranılarak ağız içi mukozayı travmatize etmemeye özen gösterildi.

Postoperatif analjezi amacıyla multimodal ağıı yaklaşımına uygun şekilde, postoperatif süreçte kaşıntı hissinden de kaçınmak için opioid dozları azaltılarak nonsteroidal ağrı kesiciler ve parasetamol tedaviye eklendi $(9,10)$. İnatçı kaşıntısı olan hastalarda gabapentin ,ondansetron gibi farkı ilaç gruplarının kullanımı da akılda bulundurulmalıdır (1). Sonuç olarak Kelebek hastalığı olarak da bilinen ve aynı kelebekler gibi kırılgan olan bu hasta grubunda peroperatif hasta yönetimine dikkat edilmeli anestezinin her aşamasında oluşabilecek komplikasyonlara karşı hazırlıklı olunmalıdır. Epidermoid Bülloza hastalarında minör travmalarla bile hastaların hayatını etkileyen lezyonlar oluşabileceği hatırda tutularak önceliğimiz tıbbın ilk kuralı olan "önce zarar verme" olmalıdır.

Etik Onam: Hasta ve hastanın birinci derece akrabalarından sözlü ve yazılı onam alınmıştır.

Etik Kurul Onayı: Dicle Üniversitesi Tıp Fakültesi Girişimsel Olmayan Klinik Araştırmalar Etik Kurulu (no:157 - Tarih: 18.05.2018)

Çıkar Çatışması: Yazarlar çıkar çatışması bildirmemişlerdir.

Finansal Açıklama: Yazarlar bu çalışmanın maddi destek almadığını beyan etmişlerdir.

\section{Kaynaklar}

1. Denyer J, Pillay E. Epidermolizis bülloza cilt ve yara bakımı için en iyi uygulama kılavuzu. Uluslararası Konsensus. DEBRA 2012

2. Torres CP, Gomes-Silva JM, Mellara TS, Carvalho LP, Borsatto MC. Dental care management in a child with recessive dystrophic epidermolysis bullosa. Braz Dent J 2011; 22: 511-6.

3. Celik E, Yıldııı ZB, Celik F, Kavak GÖ, Bıçak M. Anesthetic Management in Patients with Epidermolysis Bullosa: Two Case Reports. Turkiye Klinikleri J Anest Reanim 2018;16(2):51-6.
4. Yonker-Sell AE, Connelly LA. Twelve hour anaesthesia in a patient with epidermolysis bullosa. Can J Anaesth 1995;42:735-9.

5. Saraf SV, Mandawade NJ, Gore SK, Padhye UD, Pereira CS. Epidermolysis bullosa: Careful monitoring and no touch principle for anesthesia management. J Anaesthesiol Clin Pharmacol 2013;29:390-3.

6. Baloch MS, Fitzwilliams B, Mellerio J, Lakasing L, Bewley S, O'Suulivan $G$, Anaesthetic management of two different modes of delivery in patients with dystrophic epidermolysis bullosa. Int J Obstet Anesth 2008;17:153-8.

7. Iohom G, Lyons B. Anaesthesia for children with epidermolysis bullosa: a review of 20 years' experience. Eur J Anaesthesiol 2001;18:74554.

8. Boschin M, Ellger B, van de Heuvel I, Vowinkel T, Langer M, Hahnenkamp $\mathrm{K}$, Bilateral ultrasoung-guided axillary plexus anesthesia in child with dystrophic epidermolysis bullosa. Paeditr Anaesth 2012;22:504-6.

9. Siddiqui KM, Khan S. Anaesthetic management of an infant with epidermolysis bullosa undergoing inguinal hernia repair. J PakMed Assoc 2010;60:497-8.

10. Goldschneider KR, Good J, Harrop E, Liossi C, Lynch-Jordan A,Martinez AE, et all. Pain care for patients with epidermolysis bullosa: best care practice guidelines. BMC Medicine 2014 12:178. 